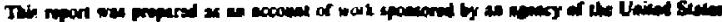

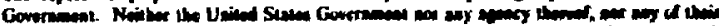

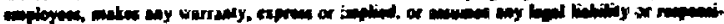

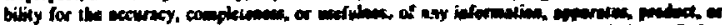

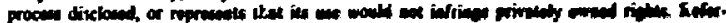

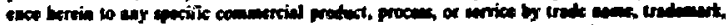

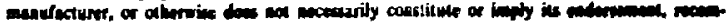

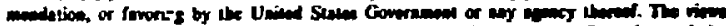

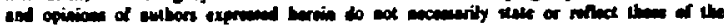

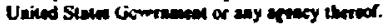

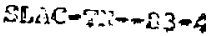

003013005

IH-135-348-00 TOIH-TASTER IHSTREGTOH MNUA.

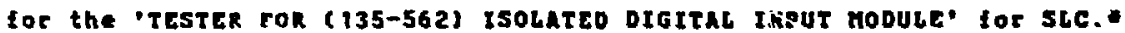

John Kieffer

Stenford in inear lccelerator center

Stantord University, Stanford, California

94305

Rev 0 , dated $83-03-16$

\title{
DISCLAIHER NOTICE
}

This document andor portions of ihe-neteriel and date furntehed herewith. was developed under the sponsorship of the U.S. Government. Meither the U.S.. not the U.S.D.o.E.. not the haland stanford Junior University, nor their eaployees, makes any barranty, express or ieplied, or ussuees any liability or responsibility for eccurecy. completesess or usefulness of any information, epparatus, produrt or process disclosed, or represents that its use will not infrinse privetely-owned rights. Mention of eny profuct, its nanulacturer, or suppliers shall not, nor is it intended :o, iaply approval, disapproval, or fitness for any particular lise. The U.S. and the University at al times reiein the right to use and disseninate sane for any purpose whatsoever.

Work supported Hy DE-ACO3-76SFOO5 15 .

the Depertinent of

of Energy, contract<smiles>C1C2CC13CC23</smiles>

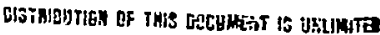

\section{MASTER}


This unit is designed to provide all of the input levels and channels needed to perfore conplete produstion eno aintenance testing of the sce Isoleted Digital Input hodule (shac 135-562).

This anual includes the following sections:

I. Specifications

2. Front Panel, Lights and Connectors

3. Reference $l i s t$

4. Functional Description

5. 825100 logic Equetions

6. Test and checkout Procedures

7. Appen'ix $A$, ShaC 825100 Prograneing Date

8. Appendix B, JXk-Fonth 135-648 Progren Listing

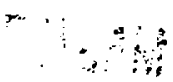




\section{Hodule specifications}

1. Module widthz single.

2. Kusber of output chennels: 32. (numbered trough 31 ).

3. Output voltage levels: ov (ground), +1YDC, +3Yoc, +5voc (YCC), +24YDC (derived fron the nodule under test), +30yoc, -30vDC, +604 pulsed.

4. Watching: 11 are outputs iatched, except that 60 volt pulsed outputs reconnect to grotind following the 1 second pulse period.

5. Response ties: 100 nicroseconds aninum lron Dateway to output.

6.

7. chrnc codes, $x$ and $Q$ responses:

a. Read functions:

1. F(0).A(0): Read selected drives $0-15, x \times Q \times 1$.

2. F(?). $(1)$ : Read selected driver 16-31. $x=Q=\{$.

3. F(1).A(0): Read control and status. $X=Q=1$.

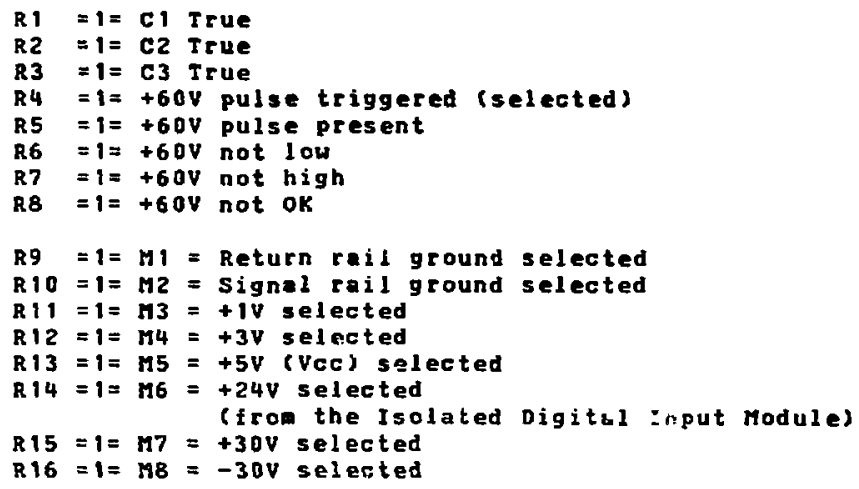

b. 


\section{Write Funotions:}

1. F(16).A(0): Hrite select drivas $0-15 . x=0=1$.

2. F(16),A(1): Hrite select drives 16-31, $x=Q=1$.

3. F(17). $(0)$ : Write voltage control. $x=a=1$. Uses 3 bitg onlys w1. W2 and w3, equivalent to Co. CI 6 C2. Bdts w4 through H24 are ignored.

The wi-w3 line octal value deteraines the module output voltage as follows:

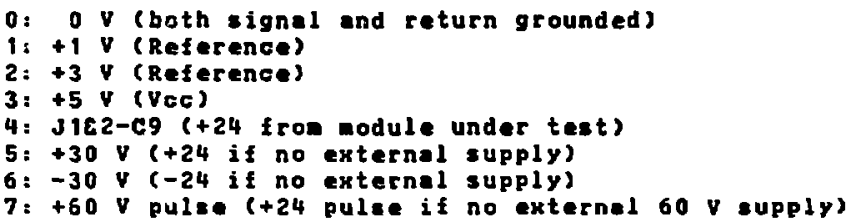

Hote: The +60 Volt signal is internally liaited to one (1) second pulse, the signal line is grounded after the pulse period ende.

c. Congend functions:

F(27).A(0); Test +60 volt supply present. $X=1, Q=1$ if $60.7 \mathrm{~V}<$ $v$ in $64.7 v$.

C. Other $X$ and a responses: $x=Q=0$ for $a 11$ other codes and conditions.

e. $c$, $z$, end $I$ : $c$, or $z$, with s2 will cles the nodule. I has no effect on this module.

8. Camac speed: the module will respond to all carac cycles as defined in IEEE Standard 583-1978.

9. Power Required: +6 volts, 700 ma. typ., 900 ah. max.

$+2^{\prime}$ volts, $60 \mathrm{AA}$. typ., $320 \mathrm{nA}(\mathrm{ax}$, when no +62V);

+62 volts (external input), $40 \mathrm{mh}$. tyo., $700 \mathrm{ma}$. sax. (if 1132 channels are pulsed together)

10. Protection: The $+6,+24$ and +60 volt lines are each protegted with a fuse consisting of a single strand of 136 tinged copper wire, fusing current is about 3.5 Amps.

1i. Cperating temperature range: 10 to 65 degrees c. 


\section{Front Proel}

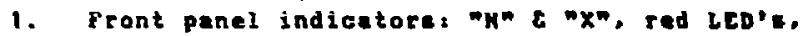

"Q" E "Yokn, green LED.

2. Front panel connectors: 1 eech BKC, $+62 \mathrm{~V}$ input:

2 each, AMP P/K 204731-1, Pin essignnents es followe;

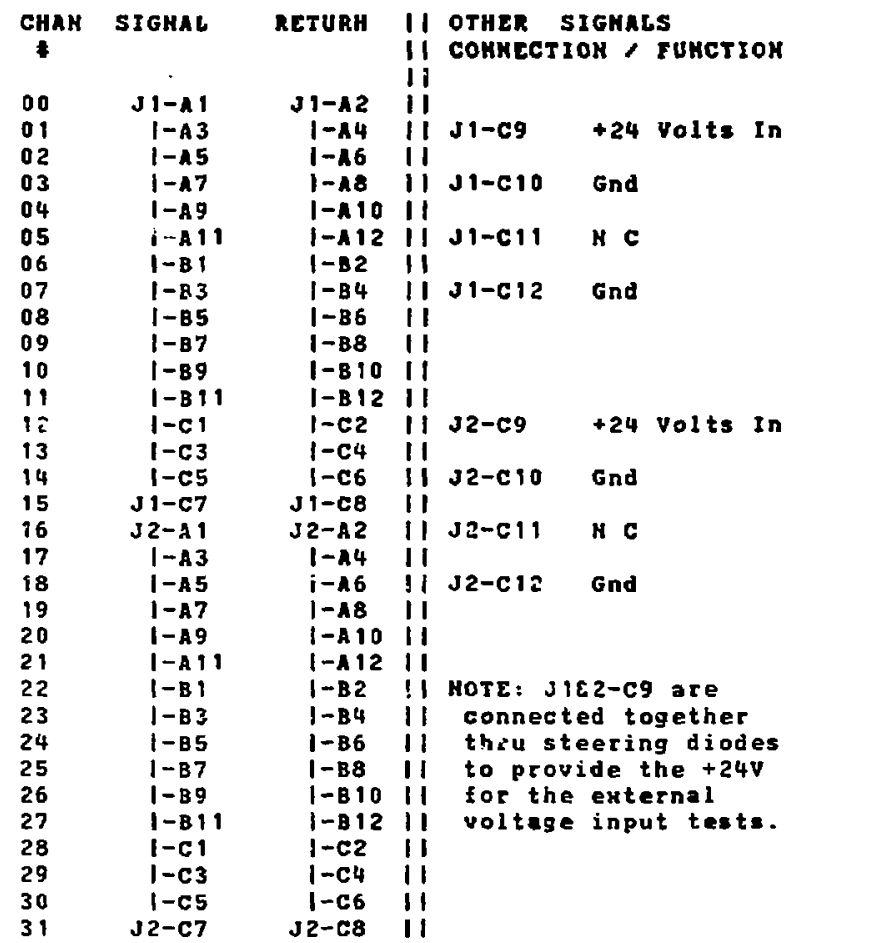




\section{Referenge wist}

1. Fuli drawing packeges $\mathrm{DL}-135-648-00$

2. Schematic on $2 y=50-135-648-00$

3. Test module: used with an Isolated Digitel Input rodyle (sinc (35-562).

4. IM-135-562-00, the IDIM Instruction Renuel (stac IK-83-0I).

5. B2s100 progranning: PS-135-648-05 \& 10 (also sea Appendix $A$ ). 


\section{Eunctional Description}

Reference: SD-135-648-00, the shenatic drawing.

The unit mey be considered in five basic sections. These are 11 the carac decoder and control section. 2) the digital I/0 section, 3 ) the level decode and pulse generator section, 4) the analog level generation section, and 5) the analog output suitching saction.

The camac decoder and control section consists of 2 rPLAs (us and U10), and the pulse extenders $(1 / 2$ of $v 19$, and 020$)$ used for the $H$, $x$, and $Q$ LED diaplays on the front panel. U5 generates the gate, strobe and latch signals needed by the digital loo section. v10, sharing identical parallel inputs with U5, generates the severel $H, X$ and $Q$ signals, as weli as the module CLEAR signal.

The digital 10 section consists of the caknc Read gates and hrite latches. U4 and 13 buffer, and invert, the canac Hrite-1ine signals, converting them to positive-true logic levels. Ug and U8, with the /WSEL-0-15 signal, latch the output pattern for channels 0-15. U14 and $U 13$, with the /WSEL-16-31 signel, latch the output pattern for channels 16-31. U17, with the /HCONTROL signal, latches the 3 bits of data that are used to select the analog output level.

The So-s31 output signals from the latches connect to both set of four CAMAC Read-line gates, and the control inputs for the 32 analog channel-selector switches. U6 and U7 gate the 0-15 channel output pattern onto the CAMAC Read lines with an RSEi-0-15 signal IF(C)A(O)I. U1 and U2 do the sane for channels $|6-3|$ with an RSEL-|6-3| |F(O)A(I)| signal. U11 is used to read out the state of the control and voltage indicator lines, and 112 gates the actual level select line to camac, both under tha control of the RCONSTAT signal [F(1)a(0)].

The level decode and pulseqenerator seetion consists of the decoder (U15), the pulse generator (U19), two sections of U18, used for signal bus grounding control, and $U$ iG, used as an 8-line inverter. U15 converts the 3 control signals (c1-c3) into one-of-eight low-ixue logic signals corresponding to the eight selectable analog reference leveis (see the f(17)A(0) cannc code in section 1$)$. Octal codes 1 through 7 re inverted through 7 sections of U16, directly generating modes H3 through M8, the control signals for six of the reference level analog switches, and the TRIG siynal for the pulse generator. (The eighth section of inverter is used to generate the /p signal during power turn-on, to clear the module).

The two special modes are $M 1$ and $M 2$, $M 1$ is the ground switch comand for the Return bus, and $M 2$ is the ground switch command for the signal bus. As the Return bus is grounded far all except octal code $6(-30 \mathrm{~V})$, the ni control signal is taken ss the high state of the /30y select line (115-9). M2 needs to be generated for three separate codes. These are a): (joth Signal and Return bisses grounded), b) 6 (-30v selected), and $c$ ) 7 (at the completion of the +6ov pulse the signal bus is returned to the ground 
gtatal. One section of 746510 is used a a lou-true input or to generate the required output (u18-12). Ua1-2 is the input for colle 0 (both grounded), and vist-1 is the input for code $6(-30 y)$. U18-13 is the input for code 7 (ground following the $60 \mathrm{~V}$ pules period) and the input signel generation is discussed below.

The control signal pulse for the $60 \mathrm{y}$ analog sitch is generated using $1 / 2$ of the dual one-shot Uig. The one-shot is normelly held in the clear state (Uig-3 low). Code signale change at the carac 51 signal's leading edge, when dete is trobed into the comand lateh U15. A code 7 signai through the inverter (U16-11, 'TRIG') removes the clear, and the one-shot

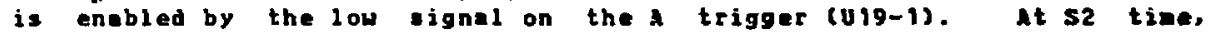
GOVSTROBE is generated by the FPLA (U5-12) and triggers the one-shot (U19-2). The PuLSE signal (U19-13) is the control for the 60 volt andiog reference suitch.

The TRIG signal (J16-11) and the CPULSE signal (U19-4) ace kakDed in in ons section of U18, and generote the /pulie-H2 signel (u18-8) at the end of the pulse period.

The enolog reference ceneretion eection consists predoninantly of discrete copponents, and the tha24 quad operational anplifier U29. Vec is derived through Q1. +12 volts is derived froe the +24 volt supply, and is used only in the generation of the vHOS-FET (2N6661) control voltages. The +24 volt reference signel is derived through steering diodes CR6 and CR7 from the IDIM under test. The IDIM-TESTER + 24 volts is used for referente voltages only in the absence of a +63-volt external supply.

+63 volts is fed to the module through the front panel anc connector (J3), CR8 and 95 . Q5 is used for module protection. Turning oft the camac crate power, with the subsequent Ioss of +24 volts. removes the biss to 05 , thus disconnecting the +63-volt supply from the remainder of the module. The control bies for $Q 5$ is derived through $Q 6$ and CRla from the +24 volt supply. CR9 protects as fron reverse bias when the +63-volt supply is removed with the cimac crate powered.

CRI and Q2 generate the +31.5 vnlt reference used for both the +30 and -30 volt tests, from the +63-valt supply. (The -30-volt signal is generated by grounding the signal bus, and connecting the Return bus to +31.5 volts.) R5 and R17 livits the power dissipation in a2 when several chennels are being tested simultaneously.

Steeri.ig diodes CR2 through CR5 ere to provide +23 supply to both the +62 an: +31 volt 1 ines in the ebsence of an externel +63-volt supply. This allows the standard software to run a general set of performance tests without the presence of +63-volt power supply. This is adequate for field testing of an IDIM, although the full tests should be run with the external +63-volt supply for production testing. or following maintenance operations upon the IDIM.

Th: +3.0 and +1.0 volt references are derived from the resistor divider chain (R23-R26). These two signals ere buffered through $2 / 4$ ths of the Ln224 (U29), and $Q 3$ and $Q 4$ respectivly. 
The reanining $2 / 4$ th: of $u 29$ is . connected as a window voltage conporator monitoring the +63-volt supply. The two resistor divider cheins (R9 through $R(4)$ compare the +62 volt level with the canke +24 volt supply. The not-low (U29-7, , VL) and not-high (J29-1, , VH) comperator output signals are MAHDed in one section of uls to generate the warning signel cYox (U18-6). The /vok signal is ted to both the status read buffer (u1)-18) and the FPLAs (U5E10-20). The /VoK signal is lso used to drive the green ' $v$ ' front panel LED, which indicates a correct +63-volts wian lighted.

The anelog output ewitghing-ection consists of 41 vmos analog suitches, and the associsted sections of DS88412 drivers. Two of the suitches the ' $A$ circuits) contain only single output FET, and are used for grounding the Signal and Return busses. The remeining 39 sutches (the 'B' circuits) each use a pair of FETs connected in a zero offset configuration as the output switches. Seven of these circuits are used to connect the selected reference voltage to the appropriate bus. The other 32 circuits are used to connect the selected 'on' channels to the signal bus.

A11 41 circuits operate in the same anner, with the exception of the single output FET of the two grounding switches. 1/6th of DS88h12 (U22 through U28) takes a positive-true TIL level coktrol signal as the input. In the quiescent state the cortrol agnal is low (false) and the 88L12 irterface output is high $(+12$ volts). This signal holds $Q 1 \lambda / B$ 'on'. with the drain at ground. The CRO56 (CRiM/B) is a 0.56 milliaspere Fet current source connected to +62 volts. When $Q 1 \mathrm{~A} / \mathrm{B}$ is binsed on, this current flows to ground through Q1A/B, and the gates of Q2A/Bea3B are held at ground potential. At this time the cutput EETs are off, i.e. in a very high inpedance state.

When a COHTROL signal is applied, the 88612 output goes to the low state (0.2 volts). This turns off Q1A/B, removing the sink for the crose current. This current now pulls up the gate(s) of Q2A/BEQ3B. suitching the 2N6661s to the low impedance state (3 Ohms each. typical). For the 39 'B' circuits, this cornects the $I N$ and ouT points with a series resistance of about 6 ohms, low enough to be distegardable when consitering the 3 kohm input impedance of ar IDIM channel.

The 2N6661 vmos-FETs, in addition to the low on resistance, are extremely fast (100 MHz range) devices. This can cause transient noise generation problems when switching the voltage and current levels needed for parallel wultiple channel testing of an tory. The solution selected was the inclusion of CiA/B as Miller integration capacitors. Slowing the turn-on and turn-off times of the output siglials. 


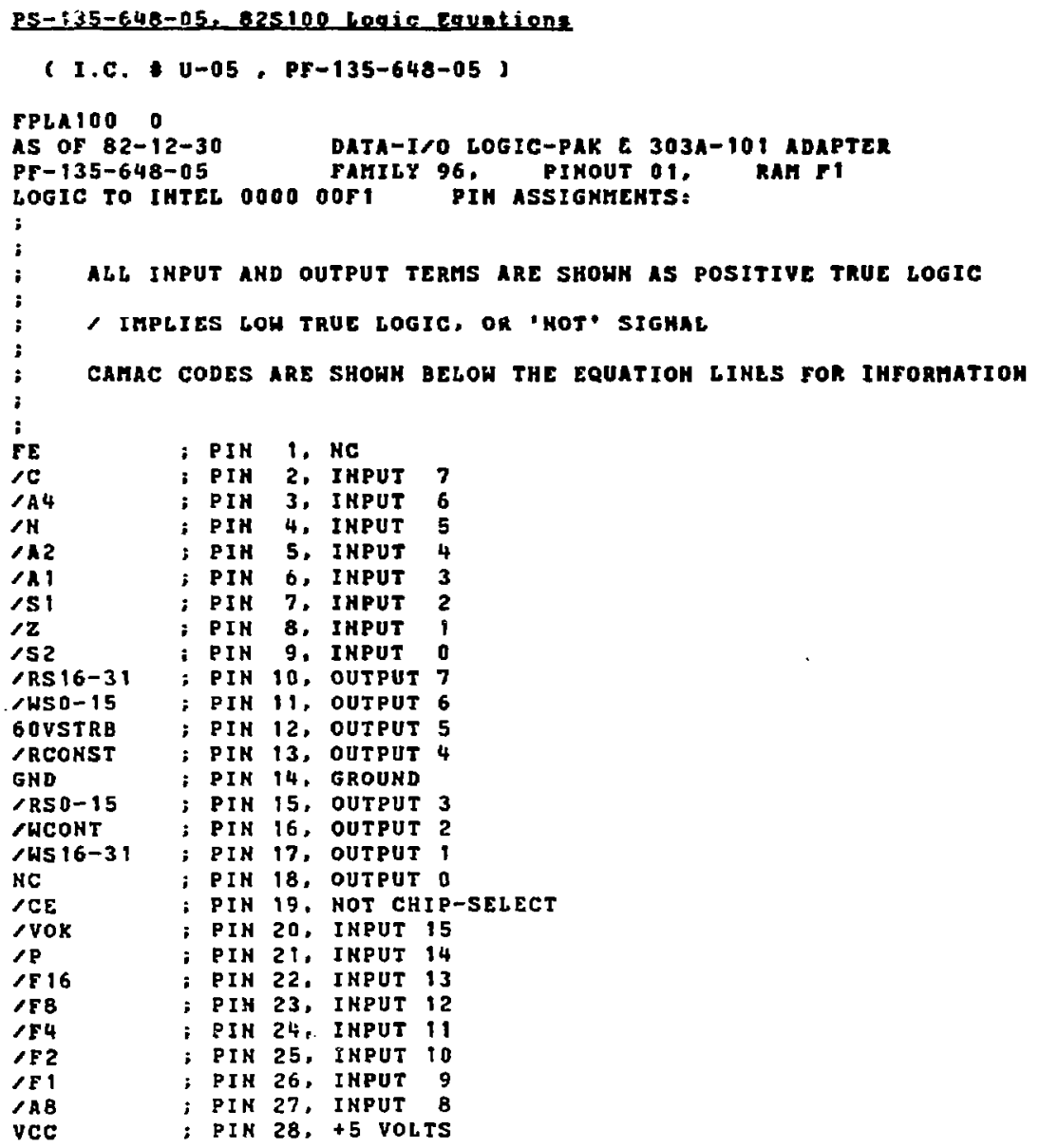




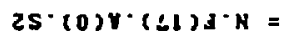

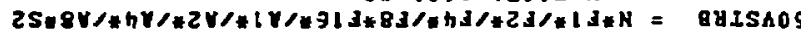
(o)Y $(1)]^{\cdot} \mathrm{H}=$

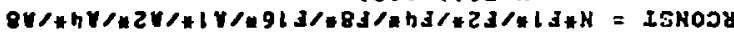

$$
61) \cdot(0) 3^{*} \mathrm{H}=
$$

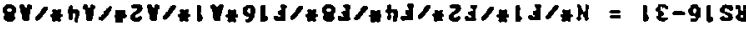
$\cos \cdot(0) \pi \cdot H=$

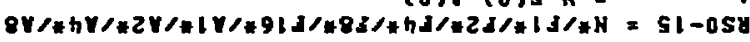
$15 \cdot(0) y \cdot(41) 3 \cdot H=$

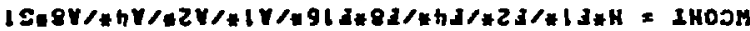
$15 \cdot(1) 4 \cdot(91) 7^{*} \mathrm{H}=$

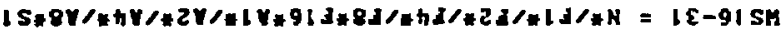
$15 \cdot(0) y \cdot(96) 1 \cdot H=$

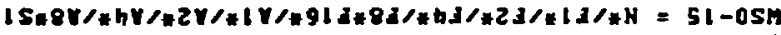
SHottunoz oI907 50-9h9-5EL-1d 


$$
\text { (1.C. U-10, Pr-135-648-10) }
$$

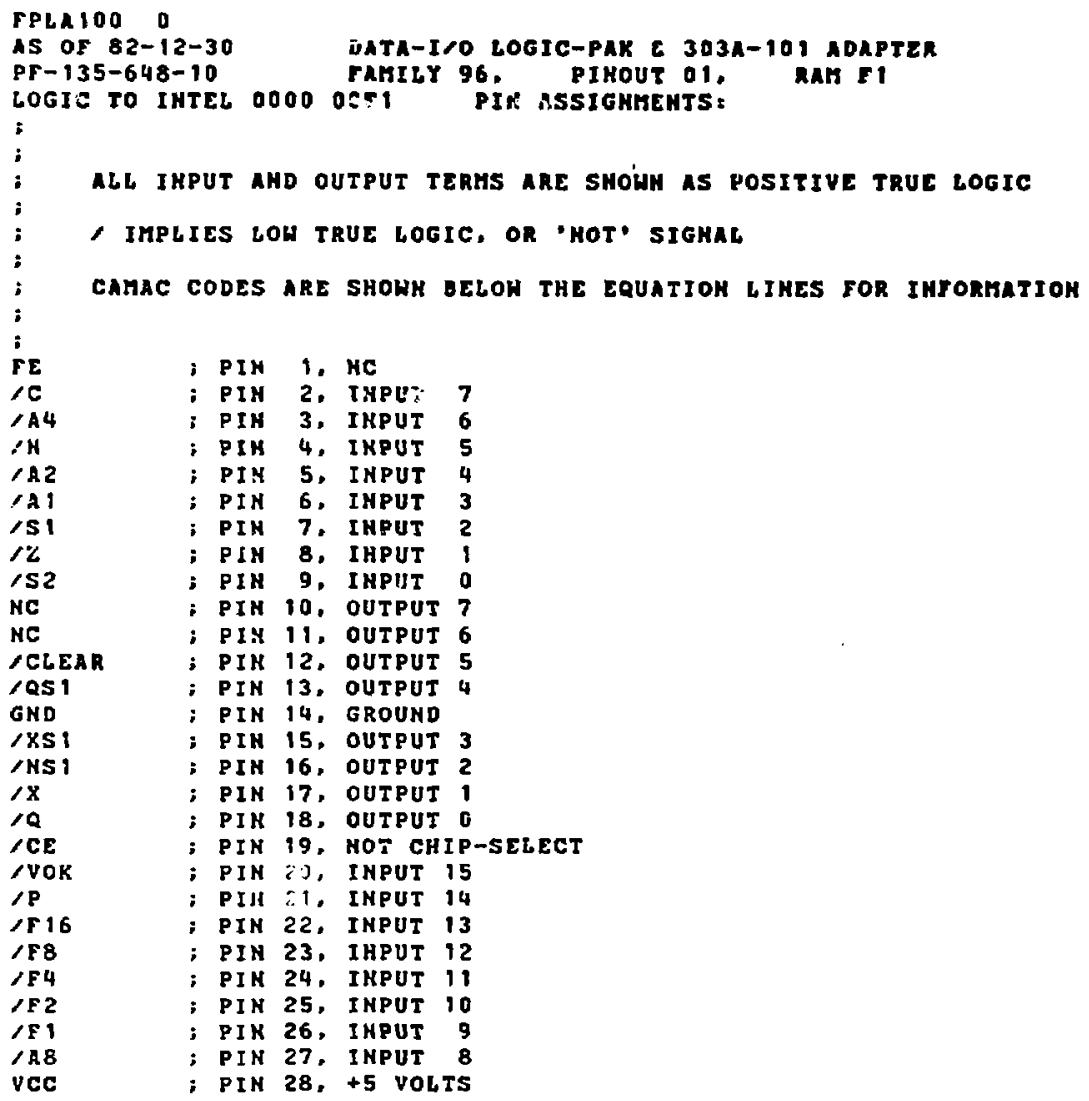


II

IH-135-648-00 IDIK-TESTER IMSTRUCTIOK MAMUAL

13

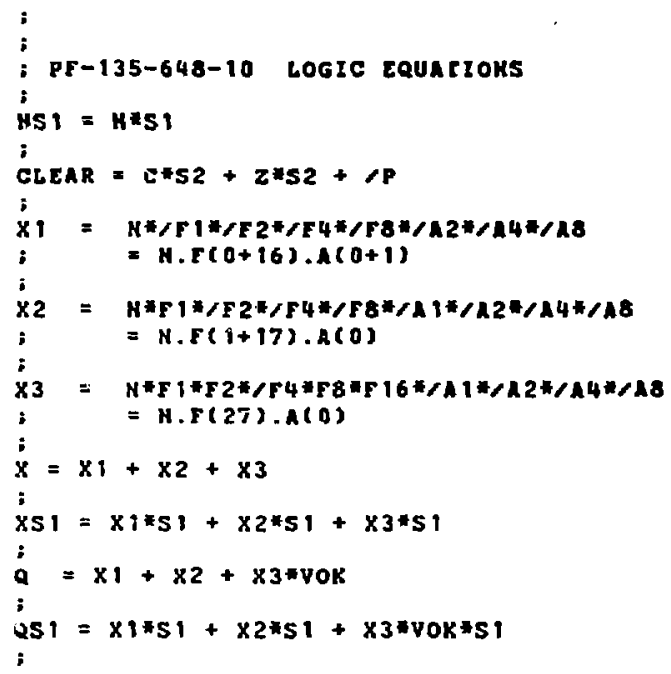




\section{Iestand checkout Procedure}

- Required equipent:

1. An LSI-tl test gtand including carac crate and a dual lloppydisk drive.

Note: Insure that the LSI-II systen will operate with carnc crate power off. Without heving to HAL?, or disconnect the carnc systen.

2. A 135-562 bodule (IDIM) known to be working.

3. A carac extender card.

4. An oscilloscope and probes

5. A digitel volt-ohmaeter and test leads.

6. A 3 koha. 1 watt, carbon composition resistor

7. A +63 Valt (0-70 volt adjustable), 100 nilliefrese, pouer eupply. including an output current monitor (aillimmeter).

Note: 100 miliageres is adequate for conplete single che..cel tests. Should slmultaneous wultiple pulsed outputs be desirad. use 0.5 AEp supply.

8. 2 each, 36-pin AMp connectored test cables.

9. A FORTH-CaMac source diskette.

10. A JXK-canac source diskette.

11. A cable to connect the +63-volt power supply to the 135-646 +63-volt input BHC connector.

12. A copy of the reterence schenatic, SD-135-648-00.

b. Setup procedure.

1. Install the diskettes, Forth-camac in Unit-o, and JxK-canac in Urit-1.

2. Install the 135-562 (IDIA) in the camac crate.

3. Turn on the $+63-v o 1 t$ power supply, and set the output to $\$ 63.0$ $+>-0.1$ volts.

4. Turn off the +63-volt power supply.

5. Apply gomputer syetem power, end bootstrap ronth. 
6. Enter '500 LOAD' to load the Jxx-FonTH systed.

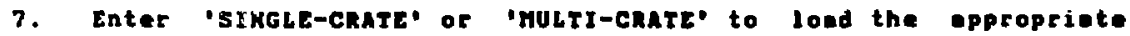
canac drivers.

8. Enter '135-64a' to load the Iorm-testen progran.

9. Enter 'GO' or '135-648-TEsis' to enter the test nenus.

10. Initiplize end tent the IRIH.

Select '135-562-TEsts'.

11. Select 'IKITIALIZE-IDIH', and respond to the proppts with the crate and sot locetions of the 135-562 (IDIM)

12. Select 'IDIn-trsis'.

13. Select 'IDIM-Maptest'. The response should bd 'MAps conpare ox". If not, re-initialize the IDIH and try agan, or ceplace the IDIM.

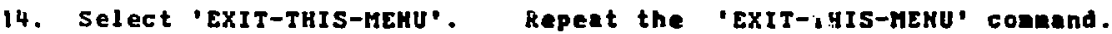
This will return to the '135-648-tests' Eenu.

c. IDIM-TESTER test procedure.

1. In perforaing the lollowing sequence of tests. each aust by passed successfully before proceeding.

should the unit fail any test, repeir and retest before continuing.

2. Remove the component-side cover.

3. Production test preliminaries.

Visually inspect the unit for obvious probleas. Conpare with a known good unit if one is available.

4. With an ohmeter, measure between ground and $+6 y,+24 y,+63 y$, and ycc, checking for direct short circuits.

5. Insure that a properly programaed set of FPLAs are installed in the IDIM-TESTER (PF-135-648-0S in U5, and PF-135-648-10 in U10).

Note: if 825100 FPLAs are installed, but not labeled with the correct PF numbers. there is a high probability that the units are HOT programed. Remove the FPLAs and install programed units. 
6. IDIy-rastrintinitiotion.

Install the 135-648 ifcis-restens on the chrnc extender, in the carnc crate.

7. Turn on the casac erate power.

B. Select 'INITIALIzE-IDIM-TEster', and respond to the propte witb the 135-648 crate end sot locations.

9. Basic $x$ and $Q$ (EPhal tents

Select 'TESTER-TESTS'.

10. Select 'TEStER-MAPTEST'. The correct response is 'MApS compare ok.'.

11. Bit pattern tents.

Select 'HALK-TESTER'. The correct response is none.

12. Select 'Control-test'. The correct response it none.

13. Iest the +53 -yolt protection cirevit $(05$ and 06$)$.

If necessary, reset the +63-volt $\because$ wer supply to 63.0 volts. and then turn off the +63-vol: power supply.

14. Connect the +53-volt power supply to the IBIM-TESTER.

15. Turn on the +63-volt power supply.

16. Observe the quiescent curreni being drawn fron the +63-volt power supply. It should be about 45 millianperss.

17. While observing the +63-volt power upply output current, turn off the carac crate power. The +63-volt power supply output current should drop to zero.

If the current does not immediately drop to zero, quickly tura off the +63-volt supply to prevent over-dissipation danage to the IDIM-TESTER components.

18. Turn on the chrac crate power. 
19. Snt ond tent the $+53-$ yolt Inyel noniter.

Heesure and record the voltages VRH (U29-3) and VRL $(429-6)$.

Deternine $V x$, the everage value of these two voltages. It should be $2.059+/-0.040$ yolth.

20. Set the voltags at v29-2 to vx (as deterained above) $+/-0.005$ volts. Adjust using the trie-pot R10.

If the calibration range of the trin-pot is not sufticient to make this edjustment, find and correct the problen, then repet the entire +63-volt test procedure before continuing.

21. Observe the 'V' LED on the front of the IDIH-IEsTEn. It should be lighted at this tise.

22. Select '62-VoLt-test'. Tha response must be 162 VOLT IMPUT OX'.

23. Set tire +63-volt supply to +67.0 volts. The 'v' ted must go dark.

Note: in no case exceed +70 volts frow the supply.

24. Select '62-voli-tesI'. The correct response is 162 volt IHPUT HIGH'.

25. Set the +63-volt supply to +59.0 volts. The $\cdots$ cEo aust be dark.

26. Select '62-Volt-TEst'. The correct response is 92 VOLT IHPUT LOW'.

27. Observing the ' $V$ ' LED on the front of the IOIM-tesTER, increase the +63-volt power supply slightly to the nid-range point of the lighted ' $y$ ' $L E D$.

Kote: again, do not exceed +70 volts from the supply.

28. Fuld IDIM-TESTER atend-alone test,

Select 'FULL-TESTER-TEST'. This is a repeat of the above individual tests, and the unit should exhibit no problese at this time.

29. Qutput level tests.

Install the 3 Koha test resistor between Ji-Al and JI-A2, (Signal and Return for channel 0 ).

30. Set the voltmeter to safe range for 60 VDC wasurements. 
31. Connect the voltweter ucross the 3 kohn test resistor. uith the positive lead to Ji-Ai.

32. Select 'OUTPUT-PATTERH-SET'.

33. Select 'TURH-OHE-OH'. Respont to the channel number proept with . 01 .

34. Selegt 'OUTPUT-VOLTAGE-SET'.

35. Select 'o-volts-our'. The voltaeter should read less tion $t /-$ 0.010 volts.

36. Select '+i-voLt-out'. The neter should reed slightly aboue +1.000 volts.

Note: should the voltage remin at zero, select a diferent channel, and wove the test resistor and voltmeter to the output connections for that channel.

If the neter still fails to read the carrect voltage. the froble ay be in either the reference voltage or channel control area.

If the reading is now correct, the problem is probebly in the channel control or channel analog switch output area.

37. Select '+3-volts-out'. The neter should read slightly below +3.000 volts.

38. Select '+5-vouts-out'. The neter should read Vcc 15.0 to 5.2 volts).

39. Select '+24-voLts-out': The meter should read zero, as this voltage is derived from an IDIM, which is not presently connected.

40. Select '+30-vouts-out'. The meter should read between +31 and +33 volts.

41. Select '-30-volts-out?. The meter should read between -31 and -33 volts. The actual value should be the negative equivalent of the positive value read in the previous test.

42. Turn off the +63-volt power supply.

43. Qutput pulse test and set.

Connect the oscilloscope across the 3 kohn test resistor in place of the voltweter. 
44. Select 'output-pulses'. The progran will begin loop generating pulses in the +20 to +24 volt range. Pulses ere triggered at en approxinatly 1.5 second rate.

Hote: stroke any key to terminate the loof.

45. Set the scope to trigger on the leading edge of the positive output pulse, and wesure the ectual pulas width.

46. The pulse width should be 1.1 seconds. An acceptable volue is between 1.0 and 1.2 seconds.

If it is not correct, change 834 ( 68 kohas as anufactured) to obtain the correct width.

$$
\text { R-new (KOhms) }=\frac{1, \text { kn-old_(KOhns) }}{\text { Tine-now (seconds; }}
$$

47. Again, select 'OutPut-puLses'.

48. While obsering the scope, turn on the +63-volt power supply.

The 20+ volt pulse amplitude should increse to epproxisatly +61.5 volts. The anplitude uus be greater than 60 volts.

49. Turn off the +63-volt power supply, and sop the pulse loop.

Hote: again, stroke eny key to terminate the loop.

50. Qutput channel tasts.

Select '+5-VOLTS-OUT'.

51. Select 'EXIT-THIS-HEKU'.

52. Select 'ALL-OK'.

53. With the voltmeter connested across the 3 kohn test resister. chack each of the 32 output channels for Vce out.

In addition. check thet mexsured value is consistent for 1132 channels, within a few (about 10) millivolts. A larger variation probably indicetes a bad analog switch.

54. Select 'ALL-OFF'.

55. Select 'EXIT-THIS-MENU'. 
56. Lorf. chonnel leakage tente.

The following four ateps chack the leaknge volues oi the 'off" channel anolog output suitehes.

57. Select '+30-volts-our'.

58. Again, measure all outputs with the voltaeter and 3 koho load. All readings should be zero (lass then 10 millivolts).

59. Select '-30-Youts-OUT'.

60. Measure all outputs with the voltaeter and 3 koho losd. Again, all readings should be zero (less than :0 millivolts).

61. 'OH' chennel ippedance.

Select 'o-volts-ouT'.

62. Select 'EXIT-THIS-MENU'.

63. Sel ect 'ALL-OK' .

64. Using a length of wire, connect one end of the 3 koha test resistor to the CaMac crate +24-volt monitor point. Connect the voltmeter between the other end of the test resistor and ground (chassis).

65. Using the common resistor-voltmeter connection as a test probe, measure each of the 32 'Signal' lines.

The voltage should be less than 84 millivolts (equal to about 9 Ohms through the 'on' analog channel-switch and the signal bus grounding analog switch). Typical values are about 42 millivolts (ar slightly under 6 ohms).

66. As above, measure any one of the 'Return' lines.

The voltage shoule be less than 40 millivolts (equal to about 4 ohws through the single Return bus grounding feT). The typical value is about 19 millivalts (or slightly under 2 ohns).

67. At this point. the only analog circuit that has not been fully tested is the +24 volt referencl $\mathrm{switch}$. As the reference voltage for this switch is derived from the IDIM module, the test of this switch is made under full load conditions as a part of the following test sequence.

68. Select 'ExIT-THIS-MENU'. Repeat the command. This will return to the '135-648-tests' menu.

69. Full tests with the IDIM. 
Select $\cdot 135-562-$ TEsts $^{\bullet}$.

70. Select 'IDIn-tests'.

7i. Connect $J i$ and 32 of the IDIM-resren to the saes conuetors of the IDIM.

72. Turn on the +63-volt power supply.

73. Select 'TEST-ALL'. The progran will indicete il there ore any problens.

74. It the systen pases the 'Test-hlb' routine, the IoIM-Tester is good. and no further teating is required.

Should the syaten fail the 'TEst-Abb' routine, anintenance is require.

Hote that probleng and develop in the IoIm that could appen as a fault in the Iorm-TESTER under test.

If the meintenance is to be done at this time, proced to the 'Maintenance procedure' section.

75. Test close-out.

Turn off the +63-volt power supriy.

76. Turn oft the camac crate pouer.

77. Return to the '135-648-rests' menu.

78. Discrinect the test cables, and remove the IDIfi-tester.

79. Replace any module covera that have been renoved.

d. Maintenonce procedure.

1. Pertora the setup and test procedures as outlined above.

2. Select between 'TESTER-TESTS', 'OUTPUT-PATTERH-SE and 'OUTPUT-VOCTAGE-SET' to obtain detailed selection of available module tests, as needed. 
3. When troubleshooting in aonjunction with an IDIM. any of the IDIf test coutines wey also prove very useful in debugging the I DIH-TESTER.

4. Should it be necessery to refurn to rokth to perfora addisionel specific tests to aid in the deteraination of a problen. a return to the test aenus is easiest done by entering the ronty comend $60^{\circ}$.

5. Listed below ere explanations of some of the teste evetlable through the test menus. The definitions ore given in the order of appearance on the various menus.

The tests not listed below are believed to be self-explanatory.

a . ALL-OK turns on all outputs to the selected voltage.

b. ALL-OFF sets all outputs to the flosting ('off') state.

c. WaLk-IMIT initializes all the walking bit tests.

d. WALK-OKE-OK walks a '1" bit through all 32 channels, outputing signals at the selected voltage.

e. WALK-OKE-OFF turns all channels on to the selected voltage, and then welks a ' $O$ ' bit through all 32 channels.

f. OUtPut-low-patterk asks for, ind then outputs, attern to the 31 channels $(0$ through 15 ).

g. OUTPUT-HIGH-PATTERH, es bove, to the J2 channels (16 through 31 ). TURK-OKE-OH asks for, and then turns on one channel.

h. TURK-OKE-OFF, as above, turning one off.

i. TESTER-MAPTEST chechs the module $x$ and $a$ responses for all combinations of function code and subaddress.

j. CoHTROL-IEST tests 211 B combinations of the 3 voltage control bits, writing and reading back the command and status registers.

$k$, WAL-TESTER does a full walking bit test, on and of $f$, at the previously selected volt:is

1. 648-LED runs the $N, X$ and $Q$ front pannel LEDs for a visual inspection. 
Appendix A, shac 825100 programing peth.

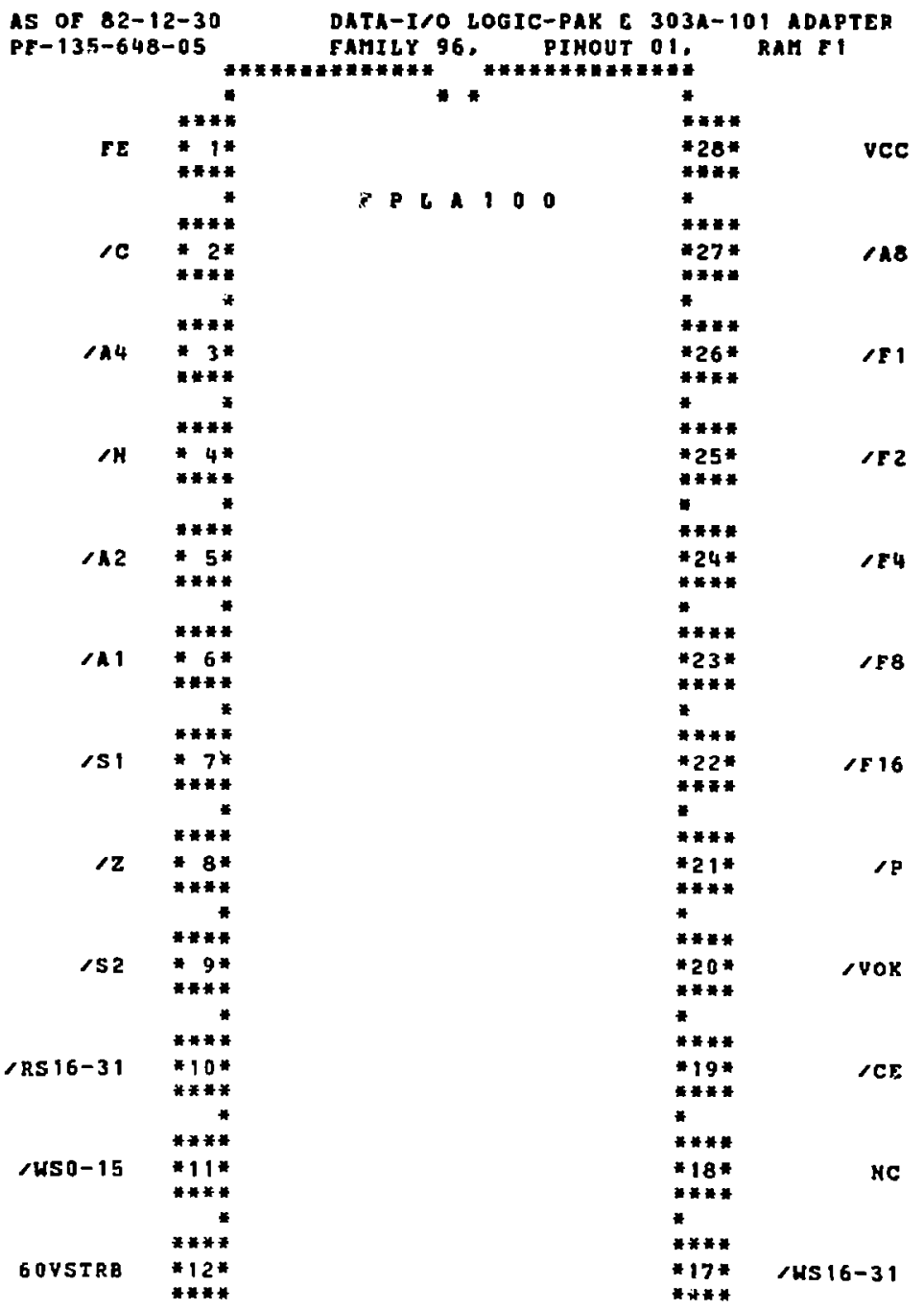




\begin{tabular}{|c|c|c|c|}
\hline & $\underset{*}{*}$ & 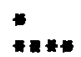 & \\
\hline /RCONST & 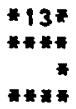 & 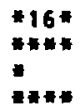 & / нокт \\
\hline GND & 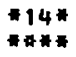 & $\begin{array}{l}* 15 * \\
* n *\end{array}$ & /RSO- 15 \\
\hline
\end{tabular}

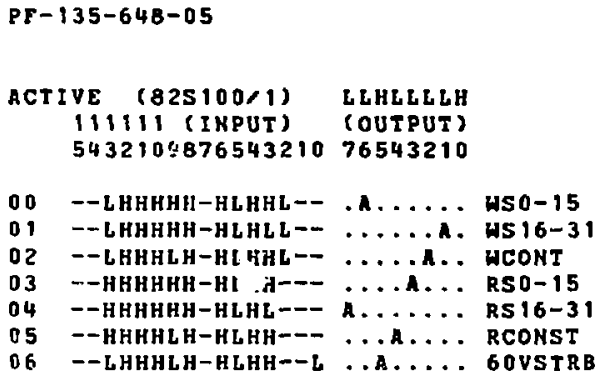




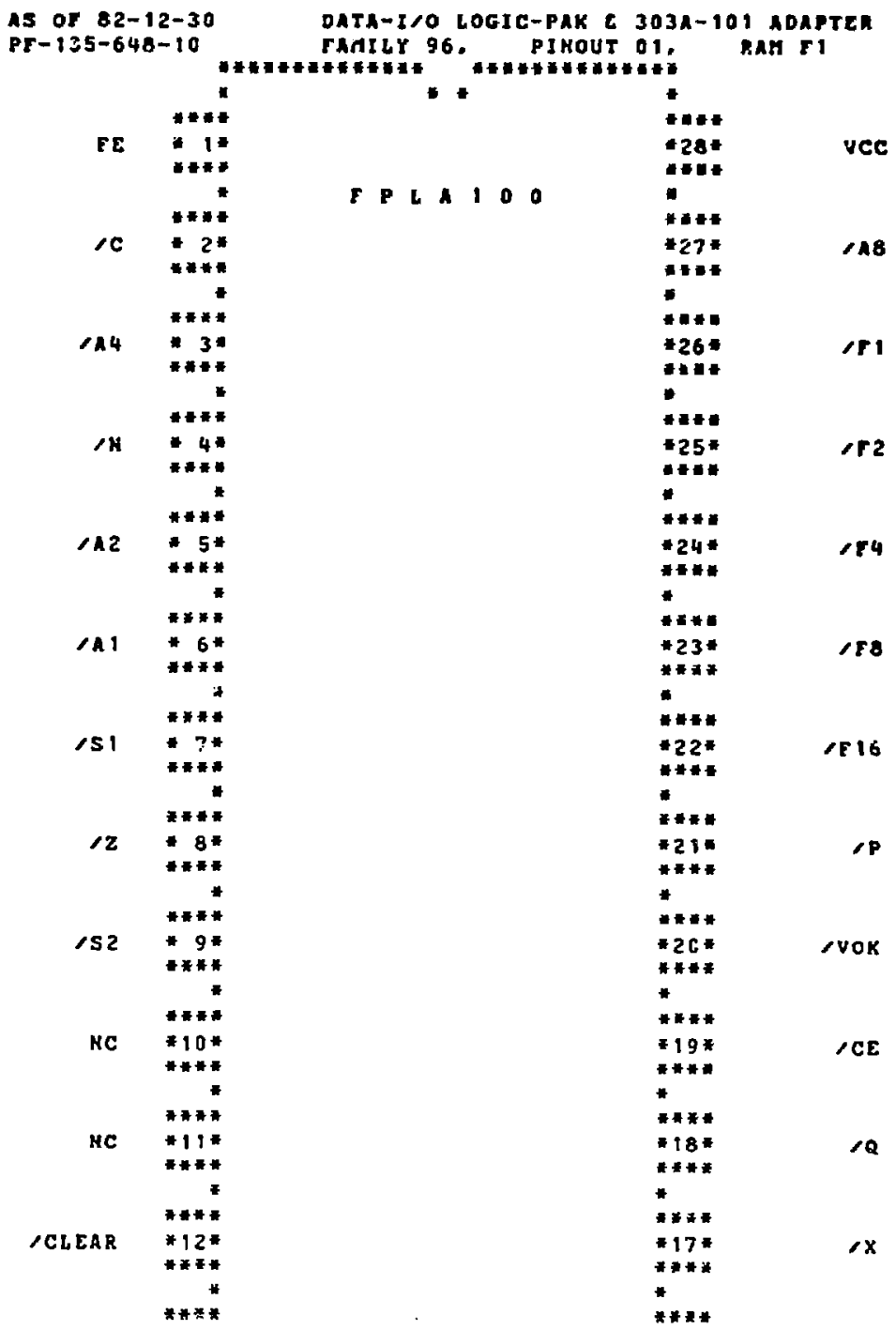




\begin{tabular}{|c|c|c|}
\hline رasi & $\begin{array}{r}13 * \\
* 4 * \\
*=4\end{array}$ & 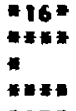 \\
\hline GMD & $\begin{array}{l}14 \% \\
=1 \%\end{array}$ & $\begin{array}{l}15 * \\
* \pm *\end{array}$ \\
\hline
\end{tabular}

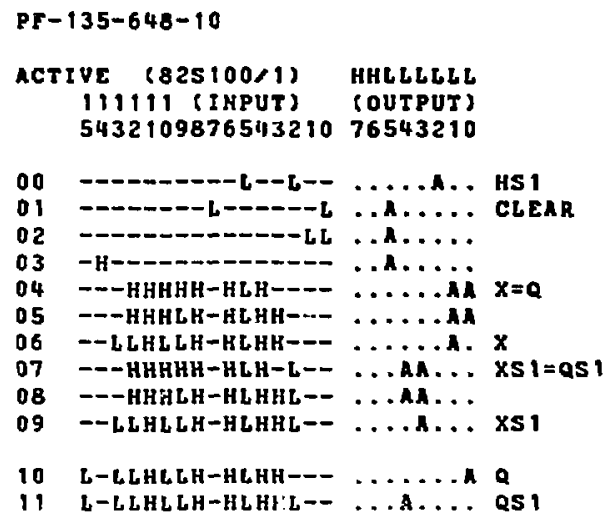




\section{IXX-FonTH 135-648-Erogrn ticting}

Hotet see lao Appendix of In-135-562-00.

Also, the letest roRTh source code for these prograse is contained in the datuset 'BUyymad roRTH', on the VH minidiak 'Jxkpus 200', on the anin shac computer conplex. 'yymed" is a 6-digit number listing the date thet the backup (BU) file was created. The highest nubber is the latect version on Ya.

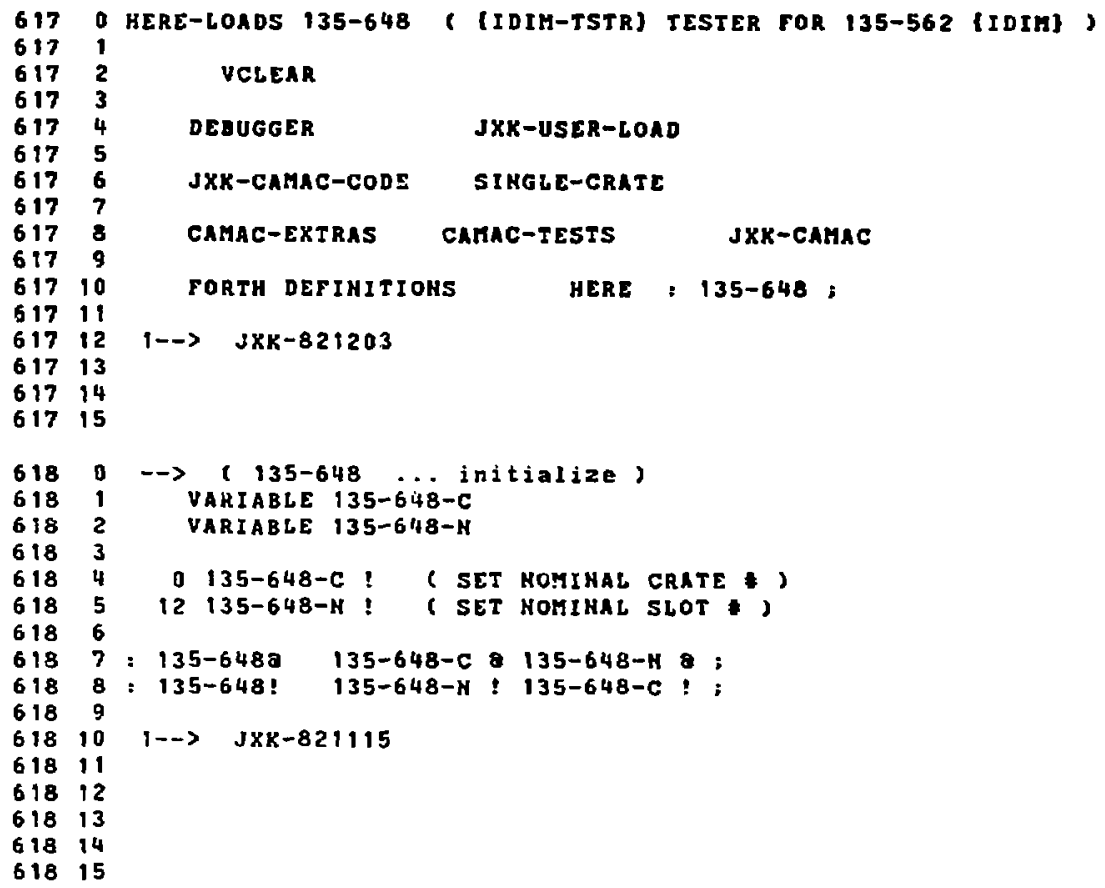




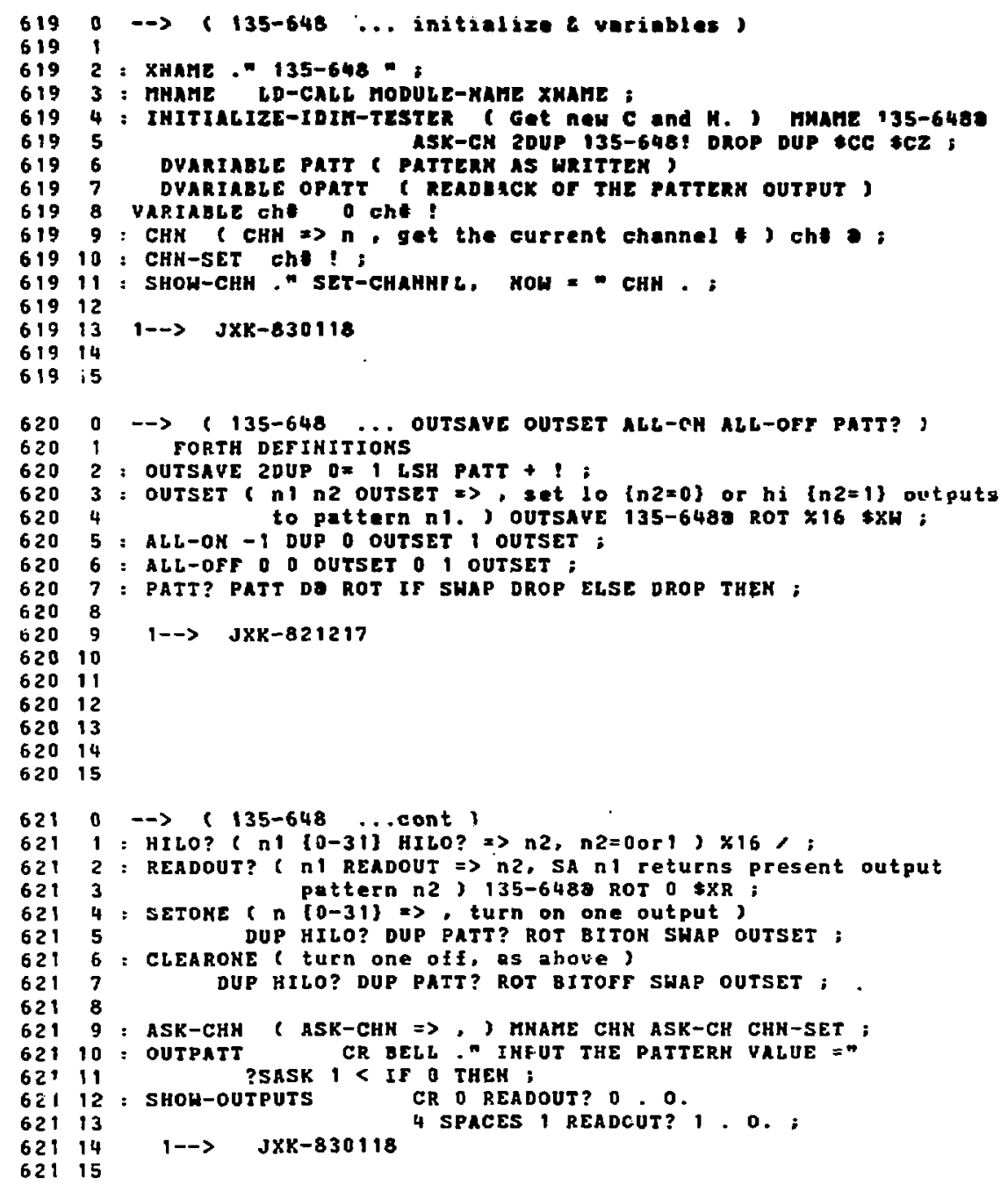




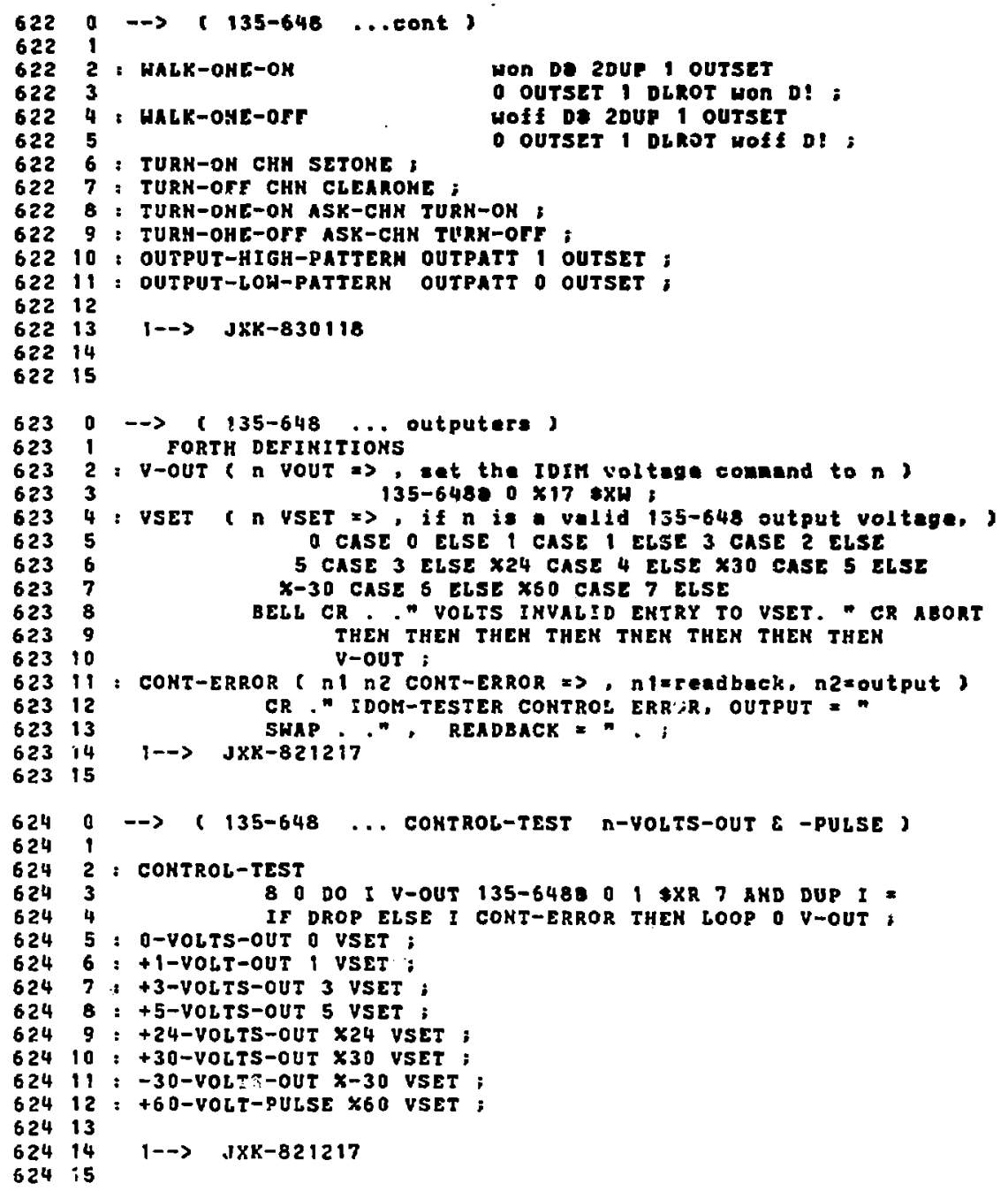




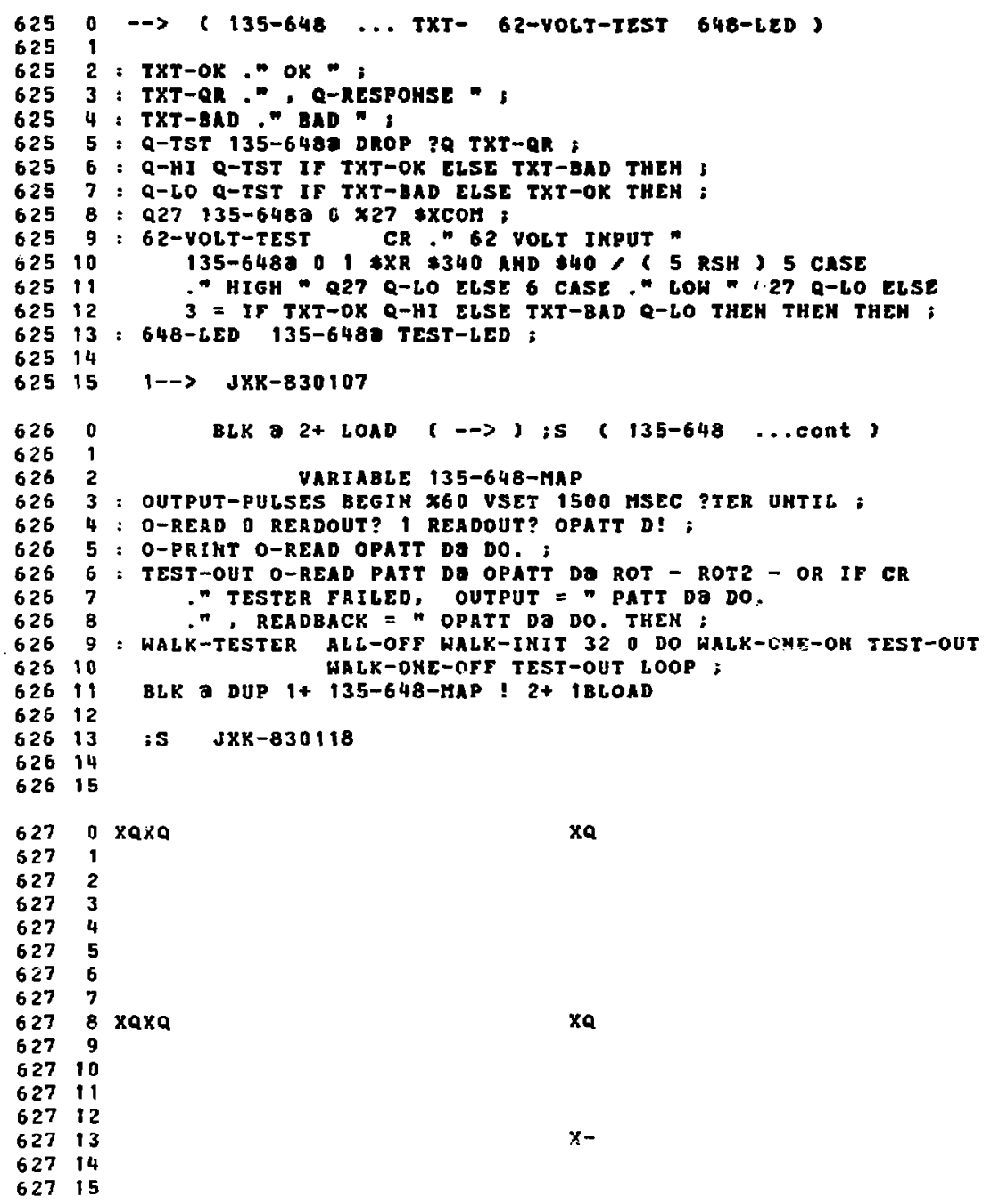




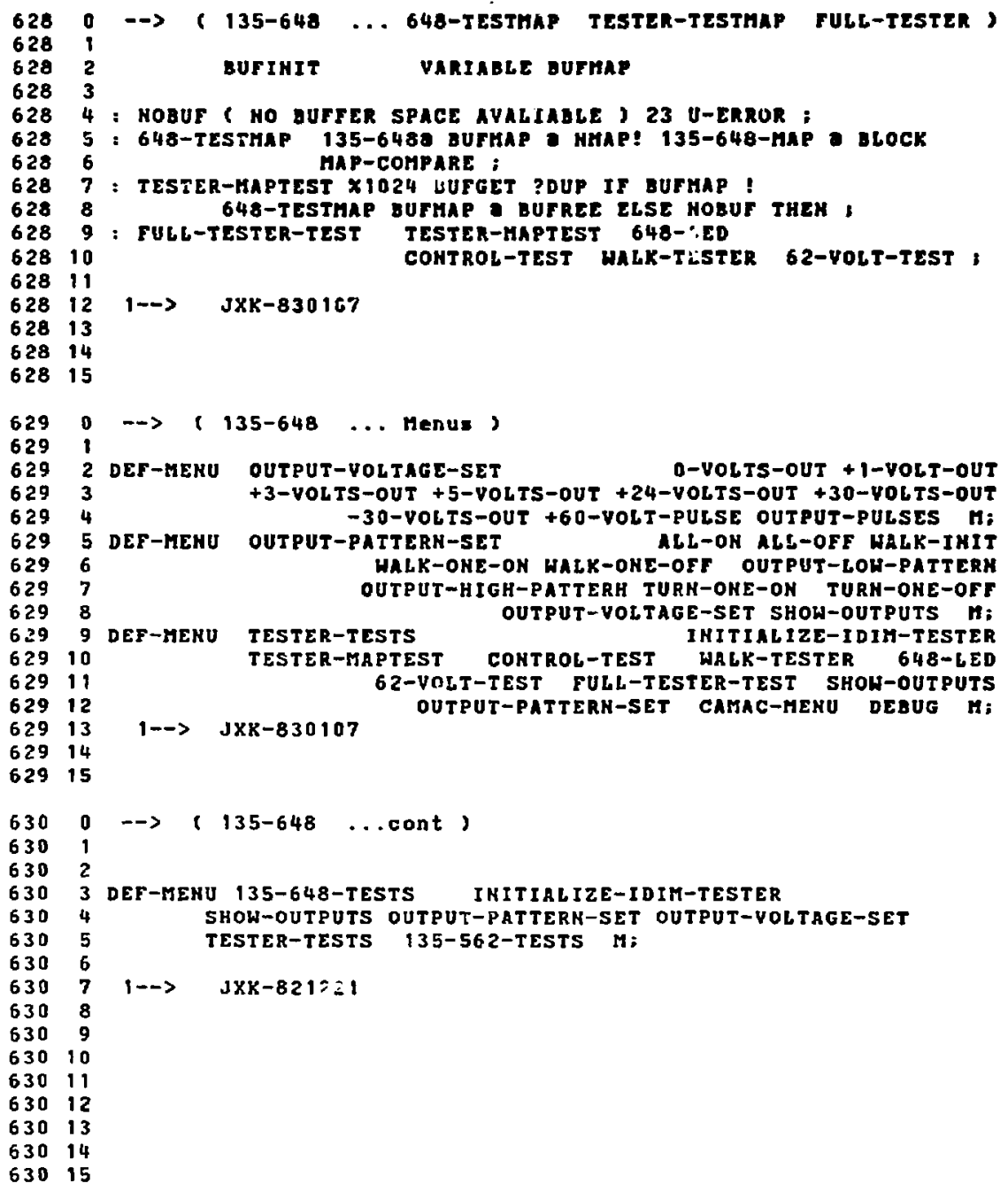




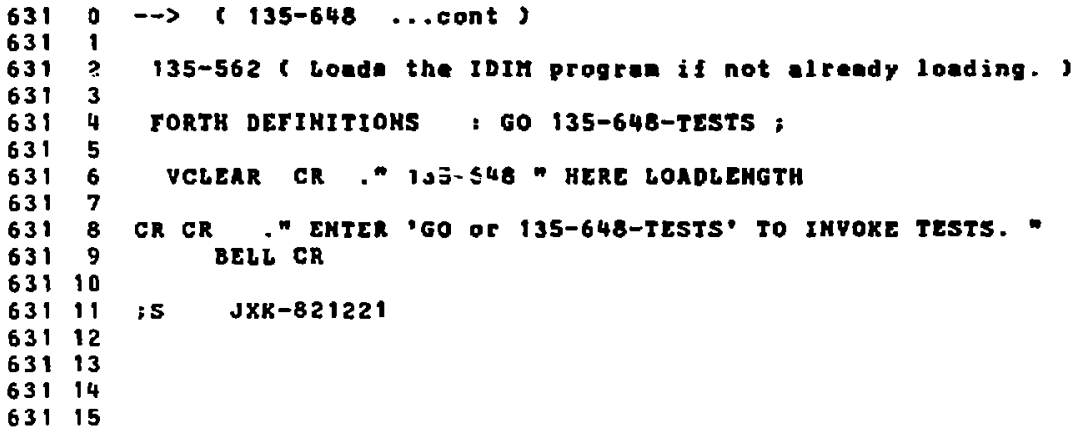

